\title{
Alpha Lipoic Acid Inhibits Expression of Intercellular Adhesion Molecule-1 (ICAM-1) in Type 2 Diabetic Mellitus Rat Models
}

\author{
Ismawati $^{1, *}$, Enikarmila Asni ${ }^{1}$, Mukhyarjon $^{2}$, Ilhami Romus ${ }^{3}$ \\ ${ }^{1}$ Department Biochemistry, Faculty of Medicine, Universitas Riau, Jl. Diponegoro No 1, Pekanbaru, Indonesia \\ ${ }^{2}$ Department of Internal Medicine, Faculty of Medicine, Universitas Riau, Jl. Diponegoro No 1, Pekanbaru, Indonesia \\ ${ }^{3}$ Department of Pathology Anatomy, Faculty of Medicine, Universitas Riau, Jl. Diponegoro No 1, Pekanbaru, Indonesia \\ *Corresponding author. E-mail: ismawatigaus@gmail.com
}

Received date: Jul 3, 2019; Revised date: Nov 18, 2019; Accepted date: Nov 20, 2019

\section{Abstract}

$\mathrm{B}$ ACKGROUND: Diabetes mellitus (DM) is associated with an accelerated atherosclerotic macrovascular disease affecting medium-sized arteries. Several evidences support the role of oxidative stress in atherogenesis. However, the role of alpha lipoic acid (ALA) to prevent atherosclerosis is still debatable. This study was conducted to determine the effect of $60 \mathrm{mg} / \mathrm{kg} /$ day ALA for 21 days toward the expression of intercellular adhesion molecule-1 (ICAM-1) in rat model.

METHODS: Eighteen male rats were divided into three groups labelled as control group, type 2 DM (T2DM) group, and T2DM+ALA group. The T2DM rat models were created by intraperitoneally injecting $50 \mathrm{mg} / \mathrm{kg}$ streptozotocin, followed by $110 \mathrm{mg} / \mathrm{kg}$ nicotinamide. Immunohistochemistry was used to evaluate the ICAM1 expression in rats. Quantitative image analysis of immunohistochemical stains was done on the abdominal aorta using Adobe Photoshop CS3 to find the area percentage and intensity. Kruskal-Wallis and MannWhitney tests were used to compare the mean value of area percentage and intensity.

RESULTS: There was an increase in area percentage and intensity of ICAM-1 expression. The highest area percentage of ICAM-1 expression was found in the DM group, while the lowest was found in the control group. There were significant differences in the area percentage and intensity between DM+ALA group and DM group, where the area percentage and intensity of ICAM-I in DM group was higher than the DM+ALA group.

CONCLUSION: In conclusion, our results demonstrate that ALA inhibits the expression of ICAM-1 in T2DM rat models.

KEYWORDS: atherosclerosis, ICAM-1, alpha lipoic acid

Indones Biomed J. 2020; 12(1): 40-4

\section{Introduction}

Diabetes mellitus (DM) is a metabolic disorder characterised by hyperglycemia resulting from insulin secretory dysfunction and/or the insulin resistance in the tissues. Type 2 DM (T2DM), a much more prevalent category of DM, is caused by a combination of resistance to insulin action and inadequate compensatory insulin secretory response. Worldwidely, the number of DM prevalence had reached up to 285 million in 2010.(1) Based on the survey conducted by World Health Organization (WHO), Indonesia is the sixth country with the biggest DM cases in the world after China, India, United States, Brazil and Mexico.(2) As a chronic disease, DM increased the risk of developing complications.

Coronary heart disease (CHD) is the most common complication that becomes the main cause of death worldwide.(3) Most CHD is instigated by atherosclerosis, which is an inflammation process primarily regarding to the medium-sized arteries, such as carotid artery, coronary 
artery, major branches of thoracic aorta, and abdominal aorta.(4) According to its clinical course, atherosclerosis is divided into several stages, including the initiation, progression, and complication stages.(5) At the initiation stage, endothelial dysfunction and activation occur because of increased oxidative stress and inflammation. Endothelial dysfunction is associated with vasorelaxant disorder due to the decreased availability of nitrite oxide (NO). Meanwhile, endothelial activation concerns the increase of nuclear factor kappa B (NF- $\mathrm{BB})$ expression and adhesion molecules, such as E-selectin, P-selectin, vascular cell adhesion molecule-1 (VCAM-1) and intercellular adhesion molecule-1 (ICAM-1).(6)

Oxidative stress has an active role in the process of atherosclerosis. A research result of the Cholesterol Lowering Atherogenesis Study (CLAS) designates that antioxidant treatment brings a significant impact towards the decline of atherosclerosis process.(7) Therefore, alpha lipoic acid (ALA), an antioxidant likely to be developed as an anti-atherosclerosis agent to DM patients, has been used to treat diabetic neuropathy patients for 30 years, especially in Germany.(8)

Some studies disclose the potency of ALA for treatment in the early stages of atherosclerosis, for example in improving the endothelial function.(9) Administration of ALA for 8 weeks could restore the endothelial functions of DM patients, as observed from the improvement of flowmediated vasodilatation (FMD) and C-reactive protein (CRP).(10) Intravenous $600 \mathrm{mg}$ ALA administration for 21 days enables the advancement of forearm blood flow (FBF) in T2DM patients.(11) However, the mechanism underlying the effect of endothelial function restoration by ALA on T2DM still has not fully understood.(9) Thus, this experimental study was conducted to analyze the effect of ALA administration to T2DM rat models, specifically toward the ICAM-1 expression on abdominal aorta.

\section{Methods}

\section{Research Design}

An experimental study with 18 Wistar rats aged 2-3 months and weighted 200-250 g was conducted. The rats were caged in a room with proper ventilation and room temperature of $20-26^{\circ} \mathrm{C}$ for 12 hours light/dark cycle. The rats' health was well maintained and its cages were cleaned every day. All procedures were approved by the Research Ethics Committee, Faculty of Medicine, Universitas Riau (No. 211/UN.19.5.1.1.8/UEPK/201).

\section{The Induction of T2DM}

The induction was conducted to 12-hours-fasted rats. The T2DM induction was completed by intraperitoneal injection of $50 \mathrm{mg} / \mathrm{kg}$ streptozotocin (STZ) and followed by intraperitoneal administration of $110 \mathrm{mg} / \mathrm{kg}$ nicotinamide after 15 minutes. The rat model was categorized as the T2DM rat model if the rat's blood glucose level was $>250 \mathrm{mg} / \mathrm{dL}$ after the third day of induction.(12) STZ was utilized for diabetes mellitus induction to the animal subjects for its cytotoxic effect on pancreatic $\beta$-cell, hence causing hyperglycemia that would raise the production of free radicals. Meanwhile, the nicotinamide was injected to reduce a defect on the pancreatic $\beta$-cell. When the STZ dose is given in a single low dose or multiple lower doses, the induction is suitable for a model of T2DM rats.(13)

\section{Experimental Design}

The experimental rats were randomly divided into 3 groups, each group consisted of 6 rats. Group I was the control group, which consisted of the healthy rats with standard diet. Group II was the T2DM group, which consisted of the rats that have been inducted with T2DM. Meanwhile, Group III was the T2DM+ALA group, which consisted of T2DM rats which was treated with ALA. As much as $60 \mathrm{mg} / \mathrm{kgBW} /$ day ALA treatment was given to the T2DM rats through nasogastric tube each day for 3 weeks.(14)

\section{Evaluation of Atherosclerosis}

The atherosclerosis assessment was done to the abdominal aorta of the rats. The abdominal aorta removal was accomplished after the rats were anesthetized with ether vapor. The aortic sample was fixed with $10 \%$ formalin buffer for 24 hours at the room temperature. A hematoxylin and eosin (H\&E) staining was performed to observe the morphological changes in the abdominal aortic in rats. The analysis was done under a light microscope with 400x magnification and at 9 fields of view. Each field of view was counted with the following scoring scheme: $0=$ normal; 1 = widening of elastic fibers with few foam cells; 2 = fragmentation of elastic lamellae with numerous foam cells and fibrosis/calcification, vascular smooth muscle cells (VCMCs) proliferation, medial lipid infiltration; and $3=$ ulcerated plaque/thrombus.(15) Score of each microscopic slide was tallied and the mean was measured. These procedures were done by the anatomic pathology specialists.

\section{Immunohistochemical Staining}

ICAM-1 expression of tissues was examined with immunohistochemistry technique using the polyclonal 
primary antibody (FineTest Company, Wuhan, China) with 1:20 dilution. The atherosclerosis paraffin tissue without any addition of antibody was used as a negative control. The area and intensity of the staining were observed under a light microscope. The ICAM-1 expression was observed using a camera microscope with 400x magnification and then gauged in 10 different fields of view. Expression of abdominal aortic adhesion molecule was calculated by Adobe Photoshop CS3 (Adobe, California, USA). The Magic Wand tool was used to select the area containing ICAM-1, meanwhile the Inverse tool was used to select the whole area of aorta. An optical density plot of the selected area was finally quantified using the Histogram tool. (16) The area percentage was presenting the comparison of area containing ICAM-1 to the whole section of the aorta, while intensity was representing the concentration of ICAM-1. Kruskal-Wallis and Mann-Whitney tests were performed to compare the mean value of area percentage and intensity.

\section{Results}

The glucose levels of 12 rats in Group II and Group III that were induced with T2DM were $>250 \mathrm{mg} / \mathrm{dL}$. Meanwhile the glucose levels of the 6 rats in Group I were $<250 \mathrm{mg} / \mathrm{dL}$.

An examination of atherosclerosis lesion on abdominal aorta was carried out using H\&E staining. The mean score of abdominal aorta histopathological features was calculated based on the microscopic slide examination results. Table 1 showed that the mean score of Group I was 0 , Group II was 2 , and Group III was $0.48 \pm 0.33$. The mean score of Group II was significantly different to Group I, and also significantly different to Group III.
Table 1. Mean score of histopathological features of abdominal aorta.

\begin{tabular}{cccc}
\hline \multirow{2}{*}{$\begin{array}{c}\text { Group } \\
\text { No. }\end{array}$} & $\begin{array}{c}\text { I } \\
\text { (Control) }\end{array}$ & $\begin{array}{c}\text { II } \\
\text { (T2DM) }\end{array}$ & $\begin{array}{c}\text { III } \\
\text { (T2DM+ALA) }\end{array}$ \\
\cline { 2 - 4 } 1 & 0 & 2 & 0 \\
2 & 0 & 2 & 2 \\
3 & 0 & 2 & 0 \\
4 & 0 & 2 & 0.89 \\
5 & 0 & 2 & 0 \\
6 & 0 & 2 & 0 \\
\hline Mean & 0 & $2^{\mathrm{a}, \mathrm{b}}$ & $0.48 \pm 0.33$ \\
\hline
\end{tabular}

${ }^{\mathrm{a}} p<0.05$ : significantly different to Group I; ${ }^{\mathrm{b}} p<0.05$ : significantly different to Group III. Tested with Kruskal-Wallis, followed by Mann-Whitney analysis.

Figure 1 showed the abdominal aorta microscopic illustration of the three groups. The Group I showed an intact blood vessel where thickening of tunica intima or foam cell were not found (Figure 1A). The thickening of tunica intima, smooth muscle proliferation and foam cell were merely exist in the Group II (Figure 1B). Figure 1C showed that the microscopic depiction of abdominal aorta in Group III, which was treated with ALA, illustrating the same abdominal aorta microscopic features as the Group I.

\section{ICAM-1 Expression}

Increasing area percentage and intensity of ICAM-1 expression was found in the media, intima and endothelium. The highest area percentage and intensity was found
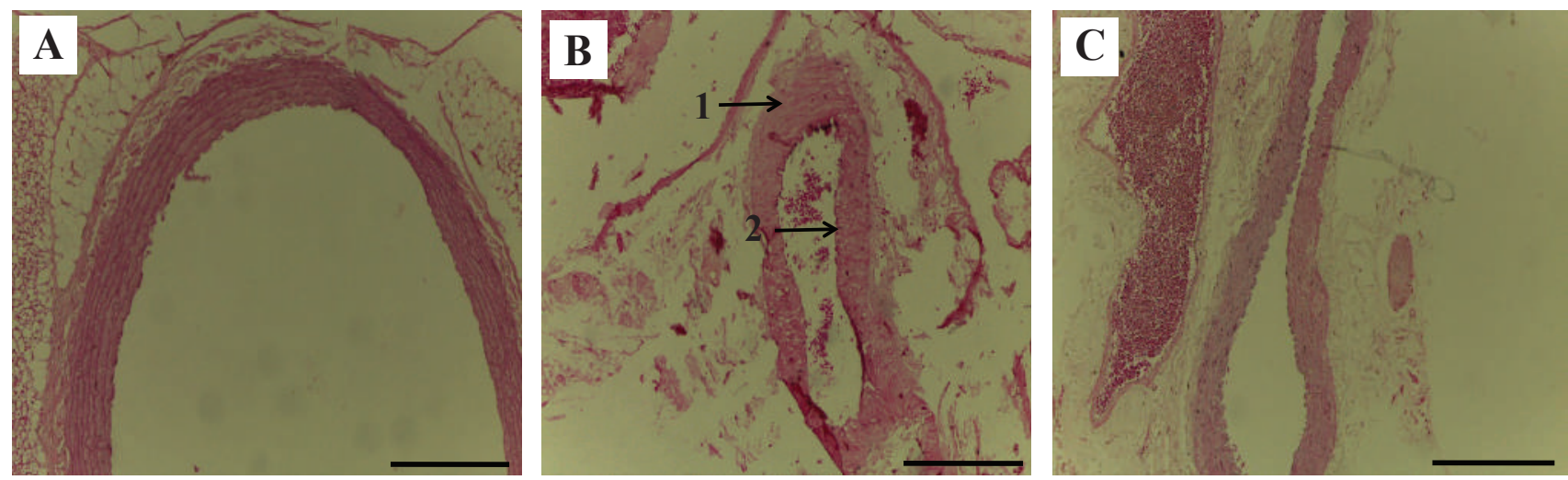

Figure 1. Abdominal aorta microscopic examination of the three groups. A: Group I (control group); B: Group II (T2DM group); C: Group III (T2DM treated with ALA group); 1: smooth muscle proliferation; 2: foam cell. Black bar: $500 \mu \mathrm{m}$. 
in Group II, while the lowest was found in Group I. The ICAM-1 expression on abdominal aorta of Group II had a significant increase compared to Group I $(p<0.05)$. On the other hand, the ICAM-1 expression of Group III had significant decrease compared to Group II (Table 2). Figure 2 also showed that the expression of ICAM-1 was significantly lower in Group III than in Group II, showed by the less Diaminobenzidine stains.

\section{Discussion}

The obtained histopathological features score of all 6 experimental rats on T2DM group were 2, which showed that a lesion in the form of intima thickening and smooth muscle proliferation were forming. When associated to the stages of atherosclerosis, this condition indicating that the experimental rats were on the progression stage.(15) The progression stage of atherosclerosis is characterized by the formation of foam cell layers and proliferation of smooth muscle cells.(6)

T2DM will induce reactive oxygen compound production on the vascular wall. Superoxide will react with nitric oxide to form peroxynitrite. This reaction will result in endothelial nitric oxide synthase (eNOS) going through uncoupling and enzyme dysfunctions, and not producing more nitric oxide.(17) Decreased nitric oxide levels stimulate an activation of NFKB (18), which is a gene transcription factor encoding the growth factors, adhesion molecules, and cytokines. The expression of
Table 2. ICAM-1 expression area percentage and intensity.

\begin{tabular}{lcc}
\hline \multicolumn{1}{c}{ Groups } & $\begin{array}{c}\text { Area Percentage } \\
(\%)\end{array}$ & $\begin{array}{c}\text { Intensity } \\
\text { (Index) }\end{array}$ \\
\hline I (Control) & $0.11 \pm 0.11$ & 0 \\
II (T2DM) & $12.41 \pm 3.02^{\mathrm{a}}$ & $34.20 \pm 7.67^{\mathrm{a}}$ \\
III (T2DM+ALA) & $2.62 \pm 1.07^{\mathrm{b}}$ & $12.21 \pm 4.41^{\mathrm{b}}$ \\
\hline
\end{tabular}

${ }^{\mathrm{a}} p<0.05$ : significantly different to Group I; ${ }^{\mathrm{b}} p<0.05$ : significantly different to Group II. Tested with Kruskal-Wallis, followed by Mann-Whitney analysis. Values are presented in mean \pm SE.

adhesion molecules, such as P-selectin and ICAM-1, will facilitate the circulating monocytes adhesion. Meanwhile, the interaction of monocytes cell and endothelial cell will cause an increased production of matrix metalloproteinase 9 (MMP-9) in penetrating the endothelial cell. As a response to colony-stimulating factor, the monocytes will further be differentiated into macrophages, and the expression of various receptors like scavenger receptor and tolllike receptors (TLRs) will occur. This scavenger receptor mediates the oxidized low-density lipoprotein (oxLDL) particle uptake by macrophages, which then instigates the construction of foam cells.(6)

In this study, the administration of $60 \mathrm{mg} / \mathrm{kgBW} /$ day ALA significantly decreased the formation of atherosclerotic lesion on T2DM rats. The atherosclerotic prevention towards T2DM rats can be perceived from the state of blood vessel that is still undamaged (intact), just like normal blood vessel. ALA suppresses the free radicals that are formed as
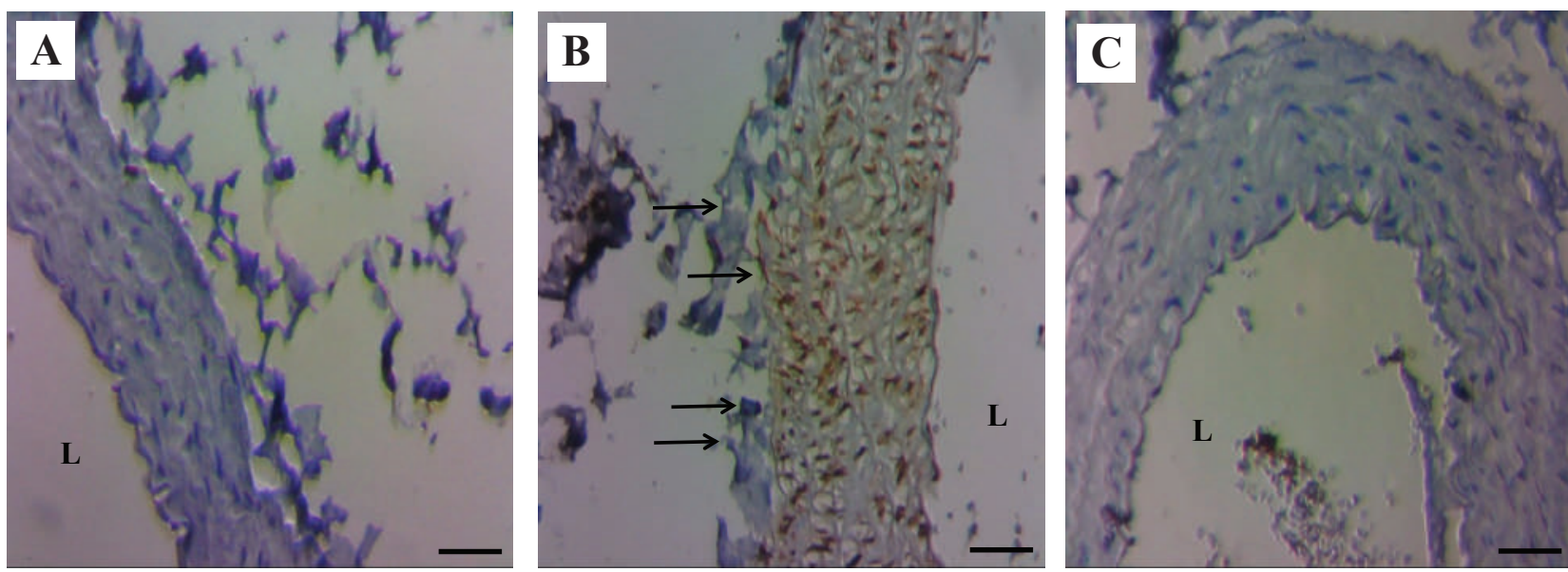

Figure 2. ICAM-1 immunohistochemical examination on abdominal aorta. Diaminobenzidine stains the ICAM-1 brown. A: Group I (control group); B: Group II (T2DM group); C: Group III (T2DM treated with ALA group); L: lumen side. Black arrows: ICAM-1 expression; black bars: $50 \mu \mathrm{m}$. 
a result of hyperglycemia, and prevents the formation of vascular lesions. Compared to other similar studies, the doses and duration of ALA treatment in this study are lesser. Administration of $100 \mathrm{mg} / \mathrm{kgBW} /$ day ALA for 8 weeks could inhibit the thoracic aortic lesions of diabetic rats.(19)

The administration of $60 \mathrm{mg} / \mathrm{kgBW} /$ day ALA for 21 days on T2DM rats has shown the effect of antiatherosclerotic. The result of this research is in accordance with a study which giving $50 \mathrm{mg} / \mathrm{kgBW} /$ day ALA treatment to diabetic rats for 3 days each week during 3 weeks. It was found that ALA could significantly repair the endothelial function of diabetic rats given a high-fat diet.(20) The $600 \mathrm{mg} / \mathrm{kgBW} /$ day ALA given for 21 days enables the improvement of endothelial function to T2DM patients.(11) This research is also in line with another study showing that administration of $60 \mathrm{mg} / \mathrm{kgBW} /$ day ALA for 2 weeks brings protective effect to atherosclerotic of rats treated with high fat diet.(14)

ALA is effective in many conditions where reactive oxygen species (ROS) have been implicated, including T2DM. Previous studies suggest that improved endothelial function due to ALA is at least partially associated with the recoupling of eNOS and increase of nitric oxide bioavailability. The mechanism of ALA anti-atherosclerotic effect through the inhibition of ICAM-1 molecule expression is related to the ability of ALA to scavenge the hydroxyl radicals, singlet oxygen, hydrogen peroxide, hypochlorous acid, peroxynitrite and nitric oxide. Besides its antioxidant role, ALA also repairs the glucose uptake by cells and also develops the nuclear erythroid 2-related factor (Nrf2), which is a transcription factor regulating the antioxidant response.(7)

\section{Conclusion}

This study indicates that ALA inhibits the expression of ICAM-1 in T2DM rat. It is suggested that ALA treatment may have important implication for preventing diabetic vascular dysfunction.

\section{Acknowledgements}

We thank to Universitas Riau, Indonesia for the Grant of 'Superior Research of Universitas Riau/Penelitian Unggulan Universitas Riau' (Grant No. 1011/UN.19.5.1.3/PP/2017).

\section{References}

1. American Diabetes Association. Diagnosis and classification of diabetes mellitus. Diabetes Care. 2014; 37(Supplement 1): S81-90.

2. International Diabetes Federation. IDF Diabetes Atlas. 8th edition. Brussels: International Diabetes Federation; 2017.

3. Manrique CM, Rosenzweig JL, Umpierrez GE. Patient information page from the hormone foundation: diabetes, dyslipidemia and heart protection. J Clin Endocrinol Metab. 2009; 94: 1-2.

4. Pyle AL, Young PP. Atheromas feel the pressure: biomechanical stress and atherosclerosis. Am J Pathol. 2010; 177: 4-9.

5. Wu JT, Wu LL. Association of soluble markers with various stages and major events of atherosclerosis. Ann Clin Lab Sci. 2005; 35: $240-50$.

6. Herrmann J, Lerman LO, Lerman A. On to the road to degradation: atherosclerosis and the proteasome. Cardiovasc Res. 2010; 85: 291302.

7. Golbidi S, Badran M, Laher I. Diabetes and alpha lipoic acid. Front Pharmacol. 2011; 2: 69. doi: 10.3389/fphar.2011.00069.

8. Yi X, Maeda N. a-Lipoic acid prevents the increase in atherosclerosis induced by diabetes in apolipoprotein E-deficient mice fed high-fat/ low-cholesterol diet. Diabetes. 2006; 55: 2238-44.

9. Park S, Karunakaran U, Jeoung NH, Jeon JH LI. Physiological effect and therapeutic application of alpha lipoic acid. Curr Med Chem. 2014; 21: 3636-45.

10. Lee SR, Jeong MH, Lim SY, Hong SN. The effect of alpha lipoic acid (thioctacid $\mathrm{hr}(\mathbb{B})$ on endothelial function in diabetic and hypertensive patients. Korean Circulation J. 2006; 36: 559-64.

11. Heinisch BB, Francesconi M, Mittermayer F, Schaller G, Gouya G, Wolzt M, et al. Alpha-lipoic acid improves vascular endothelial function in patients with type 2 diabetes: a placebo-controlled randomized trial. Eur J Clin Invest. 2010; 40: 148-54.

12. Ismawati, Mukhyarjon, Asni E, Romus I. The effect of alpha-lipoic acid on expression of VCAM-1 in type 2 diabetic rat. Anat Cell Biol. 2019; 52: 176-82.

13. Skovsø S. Modeling type 2 diabetes in rats using high fat diet and streptozotocin. J Diabetes Invest 2014; 5: 349-58.

14. Ismawati I, Winarto W, Sari RP. Pencegahan lesi aterosklerosis oleh asam alfa lipoat pada aorta mencit jantan (mus musculus) yang diberi diet tinggi kolesterol. Jurnal Ilmu Kedokteran. 2017; 5: 1925.

15. Ismawati, Oenzil F, Yanwirasti, Yerizel E. Changes in expression of proteasome in rats at different stages of atherosclerosis. Anat Cell Biol. 2016; 49(2): 99-106.

16. Lehr HA, Mankoff DA, Corwin D, Santeusanio G, Gown AM. Application of photoshop-based image analysis to quantification of hormone receptor expression in breast cancer. J Histochem Cytochem. 1997; 45: 1559-65.

17. Förstermann U, Münzel T. Endothelial nitric oxide synthase in vascular disease: from marvel to menace. Circulation. 2006; 113: 1708-14.

18. Mearini G, Schlossarek S, Willis MS, Carrier L. The ubiquitinproteasome system in cardiac dysfunction. Biochim Biophys Acta - Mol Basis Dis. 2008; 1782: 749-63.

19. Budin SB, Othman F, Louis SR, Abu Bakar M, Radzi M, Osman K, et al. Effect of alpha lipoic acid on oxidative stress and vascular wall of diabetic rats. Rom J Morphol Embryol. 2008; 50: 23-30.

20. Sena CM, Nunes E, Louro T, Proença T, Fernandes R, Boarder MR, et al. Effects of $\alpha$-lipoic acid on endothelial function in aged diabetic and high-fat fed rats. Br J Pharmacol. 2008; 153: 894-906. 